\title{
The First Characterization of HIV-1 Subtypes and Drug Resistance Mutations among Antiretrovirally Treated Patients in Kermanshah, Iran
}

\author{
Reza Golmohammadi ${ }^{\text {a }}$ Kazem Baesi ${ }^{\text {b }}$ Abdolvahab Moradi $^{\mathrm{a}} \quad$ Molood Farrokhi $^{\text {b }}$ \\ Willi McFarland $^{c}$ Shahryar Parsamajd ${ }^{d}$ \\ ${ }^{a}$ Department of Microbiology, School of Medicine, Golestan University of Medical Sciences, Gorgan, ${ }^{b}$ Department of \\ Hepatitis and AIDS, Pasteur Institute of Iran, Tehran, and ' Department of Epidemiology and Biostatistics, University of \\ California, San Francisco, CA, USA; ${ }^{d}$ Center of Counseling and Behavioral Disorders, Kermanshah University of Medical \\ Sciences, Kermanshah, Iran
}

\section{Keywords}

HIV-1 - Reverse transcriptase · Drug resistance - Kermanshah . Iran

\begin{abstract}
Background: Insufficient therapy during HIV-1 replication can promote the emergence of drug-resistant strains, reduce the effectiveness of antiretroviral treatment (ART), and increase the likelihood of the onward transmission of drugresistant viruses. We characterized, for the first time, the prevalence of HIV-1 subtypes and drug resistance mutations in a western region of Iran. Methods: This study was conducted among 122 patients on ART at a major referral center in Kermanshah, Iran. Nested PCR was performed using RT gene-specific primers from the pol gene. Sequencing was followed by amplification and purification of the desired sequence. Subtypes and mutations were determined using the Stanford HIV Drug Resistance Database. Results: Most patients (92.6\%) had subtype CRF 35-AD; 7.4\% had subtype B. In total, $36.1 \%$ of the patients had at least 1 mutation associated with resistance RT inhibitors. The greatest rates of highlevel resistance were observed for nevirapine (21.3\%) and efavirenz (19.7\%). Conclusions: Our results showed a high prevalence of drug resistance mutations in strains isolated
\end{abstract}

\section{KARGER}

(C) 2017 S. Karger AG, Basel

E-Mail karger@karger.com

www.karger.com/int from patients on treatment. At our center, we therefore recommend that genotyping be performed. This would allow the physician to prescribe appropriate drugs, reduce treatment costs, and increase the longevity and quality of life of patients.

(c) 2017 S. Karger AG, Basel

\section{Introduction}

The introduction of antiretroviral therapy (ART) has greatly improved clinical status and length of life for HIV1 -infected patients worldwide [1-3]. However, continued benefit could become elusive with the development of drug resistance. Resistance mutations have developed in the viral proteins targeted by antiretroviral drugs $[4,5]$ and are selected for when the drug fails to block virus replication [6]. In conjunction with a rapid rate of mutation, there is great genetic variation in the subtypes of HIV. Knowledge of the subtypes prevalent in particular areas may mark different patterns of transmission of the virus and correlate with the emergence of drug resistance mu-

Kazem Baesi, PhD

Department of Hepatitis and AIDS, Pasteur Institute of Iran Pasteur Ave, Tehran 1316943551 (Iran)

E-Mail kbaesi@gmail.com

Abdolvahab Moradi, $\mathrm{PhD}$

Department of Microbiology, School of Medicine, Golestan University of Medical Sciences, Falsafi Educational Campus Shaskalate, 5th km Gorgan - Tehran Rd., Gorgan (Iran)

E-Mail abmoradi@yahoo.com 
tations $[7,8]$. Monitoring clinical isolates for these mutations is needed to guide initial therapy as well as the choice of drugs following treatment failure [9].

HIV-1 reverse transcriptase (RT) involves the enhancement of resistance to all anti-AIDS drugs by causing mutations into the viral genome. At the molecular level, mutations in RT result in resistance to RT inhibitors [10].

By 2013, a recorded 27,041 individuals had been infected with HIV-1 in Iran. ART was first introduced in Iran in 1997; since then, zidovudine, lamivudine, and indinavir are most commonly prescribed for HIV patients [11]. To date, 3,250 persons diagnosed with HIV were reported in Kermanshah province, the western border of the county and the location of our study [12]. Many patients in Kermanshah have been under treatment with ART for several years, yet we have no data on the prevalence of drug resistance. This is the first study in Kermanshah to determine the profiles of drug resistance mutations in RT and the subtypes of HIV-1 in circulation.

\section{Materials and Methods}

This study was a case series comprising patients on ART who were recruited at the Behavioral Disease Consulting Center, the main referral clinic for HIV care in Kermanshah province. A total of 122 consecutive patients on ART were selected in 2013. They were on treatment and had been admitted to the Behavioral Disease Consulting Center for taking ART. As well as this, they were on ART for $>1$ year and had all provided written informed consent to participate in the study. Blood samples were taken from each patient and stored at $-80^{\circ} \mathrm{C}$.

RNA extraction from plasma was performed by using the High Pure RNA isolation kit (Roche, Germany) according to the manufacturer's instructions. PCR was performed on the reverse transcriptase (RT) gene of HIV-1 using the One Step RT-PCR kit (Qiagen, Germany). The first round of RT-PCR used the following materials and primers: $10 \mu \mathrm{L}$ RNA, $1 \times$ PCR buffer from $10 \times, 200 \mu \mathrm{M}$ of dNTP10 mM, 1.5 units of Taq DNA polymerase ( 5 units/ $\mu \mathrm{L})$, and $10 \mathrm{pM}$ of each specific primer. To amplify the $803 \mathrm{bp}$ of the RT gene, RT-PCR was performed with the outer forward $\left(5^{\prime}\right.$-GTTGACTCAGATTGGTTGCAC- $\left.3^{\prime}\right)$ and reverse (5'-GTATGTCATTGACAGTCCAGC- $3^{\prime}$ ) primers under the following cycling conditions: $50^{\circ} \mathrm{C}$ for $45 \mathrm{~min}$ (cDNA synthesis), initial denaturation at $94^{\circ} \mathrm{C}$ for $15 \mathrm{~min}$, and 35 cycles for synthesis of DNA from cDNA with denaturation at $94^{\circ} \mathrm{C}$ in $30 \mathrm{~s}$, annealing at $57^{\circ} \mathrm{C}$ in $30 \mathrm{~s}$, extension at $72^{\circ} \mathrm{C}$ in $50 \mathrm{~s}$, and the final heating step at $72^{\circ} \mathrm{C}$ for $5 \mathrm{~min}$. In the second round of RT PCR, $4 \mu \mathrm{L}$ of DNA was used as the template with the same temperature programs as in the first round for the nested PCR by using inner forward primer $\left(5^{\prime}\right.$-GGATGGCCCAAAAGTTAAAC- $\left.{ }^{\prime}\right)$ and reverse inner primer $\left(5^{\prime}\right.$-TATCAGGATGGAGTTCATAAC- $\left.3^{\prime}\right)$. PCR products (665 bp) were detected on $2 \%$ agarose gel.

The PCR products were purified using QIAquick gel extraction kit (Qiagen, Germany) according to the manufacturer's instructions, and sequenced in an automated DNA sequencer (ABI
Table 1. Transmission risks of antiretrovirally treated patients $(n=122)$

\begin{tabular}{lclr}
\hline $\begin{array}{l}\text { Transmission } \\
\text { risk }\end{array}$ & $\begin{array}{l}\text { Female } \\
\text { patients }\end{array}$ & $\begin{array}{l}\text { Male } \\
\text { patients }\end{array}$ & Total \\
\hline Intravenous drug use & $1(2.4 \%)$ & $61(76.3 \%)$ & $62(50.8 \%)$ \\
Spouse infected & $25(59.5 \%)$ & $4(5.0 \%)$ & $29(23.8 \%)$ \\
Sexual & $11(26.2 \%)$ & $4(5.0 \%)$ & $15(12.3 \%)$ \\
Mother-to-child & $3(7.1 \%)$ & $2(2.5 \%)$ & $5(4.1 \%)$ \\
Unknown & $2(4.8 \%)$ & $9(11.3 \%)$ & $11(9.0 \%)$ \\
\hline Total & $42(34.4 \%)$ & $80(65.6 \%)$ & $122(100 \%)$ \\
\hline
\end{tabular}

PRISM 3730 v3.0, Applied Biosystems, USA). The sequences were edited using Bioedit software. Subtypes and mutations were identified by the Stanford HIV Drug Resistance Database (http://hivdb. stanford.edu) [13].

The study protocol was reviewed and approved by the Ethics Committee of Golestan University of Medical Sciences.

\section{Results}

Of the 122 patients, $80(65.6 \%)$ were male and 42 $(34.4 \%)$ were female. Over three-quarters $(76.3 \%)$ of the male patients were intravenous drug users, whereas the majority of female patients (59.5\%) were likely infected via their husbands (Table 1). The mean age was $38 \pm 9$ years. The average CD4 count was $250 \pm 19$ per $\mathrm{mL}$ of blood.

One hundred patients $(82.0 \%)$ were taking the firstline regimen of lamivudine (3TC), zidovudine (AZT), and efavirenz (EFV). Thirteen (10.7\%) were taking 3TC, AZT, and nevaripine (NVP); 9 (7.37\%) were taking 3TC, tenofovir (TDF), and EFV.

The most common HIV-1 subtype was CRF35_AD, detected in 113 patients (92.6\%). Nine patients (7.4\%) had subtype $B$.

In total, 44 patients (36.1\%) had mutations associated with resistance to at least one RT inhibitor drug and 22 patients (18.0\%) had mutations associated with resistance to both nucleoside reverse transcriptase inhibitor (NRTI) and non-nucleoside reverse transcriptase inhibitor (NNRTI) class drugs. Table 2 lists the frequency of clinically significant mutations identified in the patient population in both these drug classes. The most common RT gene mutations associated with drug resistance in the NRTI class were M184V, M41L, K70R, T69P, D67N, K219E, and V75M. Common RT gene mutations associated with drug resistance in the NNRTI class were K103N,
34

Intervirology 2017;60:33-37

DOI: $10.1159 / 000478701$
Golmohammadi/Baesi/Moradi/Farrokhi/

McFarland/Parsamajd 
Table 2. Frequency of clinically significant ART drug resistance mutations among ART-treated patients $(n=122)$

\begin{tabular}{|c|c|c|c|}
\hline $\begin{array}{l}\text { NRTI } \\
\text { mutations }\end{array}$ & $n(\%)$ & $\begin{array}{l}\text { NNRTI } \\
\text { mutations }\end{array}$ & $n(\%)$ \\
\hline M184V & 17 (13.9) & $\mathrm{K} 103 \mathrm{~N}$ & $18(14.8)$ \\
\hline M41L & $6(4.9)$ & E138A & $10(8.2)$ \\
\hline K70R & $5(4.1)$ & $\mathrm{P} 225 \mathrm{H}$ & $6(4.9)$ \\
\hline T69P & $5(4.1)$ & G190A & $6(4.9)$ \\
\hline D67N & $4(3.3)$ & V179F & $3(2.5)$ \\
\hline K219E & $4(3.3)$ & Y181S & $3(2.5)$ \\
\hline V75M & $4(3.3)$ & V108I & $3(2.5)$ \\
\hline M184I & $2(1.6)$ & $\mathrm{K} 238 \mathrm{~N}$ & $3(2.5)$ \\
\hline $\mathrm{T} 215 \mathrm{Y}$ & $2(1.6)$ & V106I & $3(2.5)$ \\
\hline L210W & $2(1.6)$ & A98G & $2(1.6)$ \\
\hline L74I & $2(1.6)$ & $\mathrm{H} 221 \mathrm{Y}$ & $2(1.6)$ \\
\hline K219E & $2(1.6)$ & F227L & $2(1.6)$ \\
\hline V75L & $2(1.6)$ & $\mathrm{K} 101 \mathrm{E}$ & $2(1.6)$ \\
\hline Y115F & $2(1.6)$ & V90I & $2(1.6)$ \\
\hline D67G & $2(1.6)$ & Y188C & $2(1.6)$ \\
\hline D67F & $1(0.8)$ & V179T & $2(1.6)$ \\
\hline F77L & $1(0.8)$ & V179L & $1(0.8)$ \\
\hline K65R & $1(0.8)$ & G190R & $1(0.8)$ \\
\hline K70G & $1(0.8)$ & E138K & $1(0.8)$ \\
\hline M184G & $1(0.8)$ & P236L & $1(0.8)$ \\
\hline M184R & $1(0.8)$ & M230L & $1(0.8)$ \\
\hline L74V & $1(0.8)$ & L100F & $1(0.8)$ \\
\hline T215P & $1(0.8)$ & G190I & $1(0.8)$ \\
\hline V75G & $1(0.8)$ & G190T & $1(0.8)$ \\
\hline A62V & $1(0.8)$ & Y188F & $1(0.8)$ \\
\hline T215S & $1(0.8)$ & Y181T & $1(0.8)$ \\
\hline T215A & $1(0.8)$ & $\mathrm{Y} 181 \mathrm{~F}$ & $1(0.8)$ \\
\hline $\mathrm{T} 215 \mathrm{~F}$ & $1(0.8)$ & Y181C & $1(0.8)$ \\
\hline
\end{tabular}

ART, antiretroviral therapy; NRTI, nucleoside reverse transcriptase inhibitor; NNRTI, non-nucleoside reverse transcriptase inhibitor.

E138A, P225H, G190A, V179F, Y181S, V108I, K238N, and V106I. The most common mutation associated with resistance to NRTIs was M184V, which occurred in 17 patients (13.9\%). The most common mutation associated with resistance to NNRTIs was $\mathrm{K} 103 \mathrm{~N}$, and it occurred in 18 patients $(14.8 \%)$.

The most common mutations detected among the 100 patients on the 3TC/AZT/EFV regimen were: K103N $(n=14), \mathrm{M} 184 \mathrm{~V}(n=13), \mathrm{E} 138 \mathrm{~A}(n=9), \mathrm{P} 225 \mathrm{H}(n=4)$, G190A $(n=3)$, M41L $(n=2)$, and K70R $(n=2)$. The mutations detected in the 13 patients on the $3 \mathrm{TC} / \mathrm{AZT} / \mathrm{NVP}$ regimen included: M41L $(n=2)$, E138A $(n=1)$, G190A $(n=1)$, and K70R $(n=1)$. The mutations detected in the 9 patients on the $3 \mathrm{TC} / \mathrm{TDF} / \mathrm{EFV}$ regimen were: K103N

Drug Resistance Mutations among

HIV-Infected Patients, Kermanshah, Iran $(n=4), \operatorname{M184V}(n=4), \mathrm{M} 41 \mathrm{~L}(n=2), \mathrm{G} 190 \mathrm{~A}(n=2)$, $\mathrm{P} 225 \mathrm{H}(n=2)$, and K70R $(n=2)$.

Table 3 shows the levels of susceptibility and resistance based on the different mutations. Most patients were susceptible to the NRTI regimens that included 3TC (82.0\%), AZT (91.0\%), and TDF (91.8\%), and to the NNRTI regimens that included EFV (75.4\%) and NVP (74.6\%). Mutations associated with high-level resistance to 3TC and emtricitabine (FTC) were present in the isolates of 19 patients (15.5\%). Although EFV was part of the first-line therapy for 10 patients, mutations associated with highlevel resistance to EFV were detected in the isolates of 24 patients (19.7\%). Mutations associated with high-level resistance to NVP were detected in the isolates of $26 \mathrm{pa}-$ tients $(21.3 \%)[14,15]$.

\section{Discussion}

For the first time in the western Iranian province of Kermanshah, we reported the HIV-1 strain subtypes and resistance mutations among patients on ART. The HIV-1 subtype CRF35_AD predominated, accounting for $>90 \%$ of isolates. Subtype B was also found. The most important mutation associated with NRTI drug resistance was M184V and the most important mutation associated with NNRT drug resistance was K103N. Both mutations were detected in approximately $1 / 7$ patients treated with these drugs. Mutations associated with high-level resistance to 3TC, EFV, and NVP were detected in approximately $1 / 5$ patients taking these ART drugs.

Some studies have been performed on drug resistance mutations and HIV genotyping in Iran, most of them in Tehran and at the national referral center in the capital. In 2010, Hamkar et al. [16] found subtype CRF 35_AD in approximately half (48\%) of their patients on ART (in Tehran). Our data were more similar to 2 other studies by Baesi et al. [17, 18] (in 2015) which found a frequency of 80 and $88 \%$ CRF 35_AD. In 2016, a third study by Baesi's group (Farrokhi et al. [19]) found the frequency of CRF35_AD to be $96.1 \%$. These findings are also consistent with an earlier national pilot study by Mousavi et al. [20] (in 2010) which found subtype CRF35_AD to be the most common in Iran.

The prevalence of drug resistance mutations in this study, where $36 \%$ of patients had at least 1 mutation, was lower than the 58\% reported in Iran in 2014 [21]. We found that the most prevalent mutation associated with NRTI drug resistance was M184V, which causes resistance to 3TC and FTC. However, our prevalence of 13.9\%

Intervirology 2017;60:33-37 DOI: $10.1159 / 000478701$ 
Table 3. Levels of resistance to drugs in antiretrovirally treated patients $(n=122)$

\begin{tabular}{|c|c|c|c|c|c|c|}
\hline \multirow[t]{2}{*}{ Level of resistance } & \multicolumn{4}{|c|}{ NRTIs, $n(\%)$} & \multicolumn{2}{|c|}{ NNRTIs, $n(\%)$} \\
\hline & $3 \mathrm{TC}$ & AZT & TDF & FTC & $\mathrm{EFV}$ & NVP \\
\hline Sensitive & $100(82.0)$ & $111(91.0)$ & $112(91.8)$ & $100(82.0)$ & $92(75.4)$ & $91(74.6)$ \\
\hline Low & $2(1.6)$ & $3(2.5)$ & $4(3.2)$ & $2(1.6)$ & $5(4.1)$ & $4(3.2)$ \\
\hline Intermediate & $1(0.8)$ & $5(4.1)$ & $3(2.5)$ & $1(0.8)$ & $1(0.8)$ & $1(0.8)$ \\
\hline High & $19(15.6)$ & $3(2.5)$ & $3(2.5)$ & $19(15.9)$ & $24(19.7)$ & $26(21.3)$ \\
\hline
\end{tabular}

NRTIs, nucleoside reverse transcriptase inhibitors; NNRTIs, non-nucleoside reverse transcriptase inhibitors; 3TC, lamivudine; AZT, zidovudine; TDF, tenofovir; FTC, emtricitabine; EFV; efavirenz; NVP, nevirapine.

is lower than the previously reported range of $19-60 \%$ in patients throughout Iran over the last several years [16, $22,23]$. The most prevalent mutation associated with NNRTI drug resistance in our study was K103N (in $14.8 \%$ ), also lower than the $29 \%$ reported in a prior study of patients treated in Tehran in 2010 [16]. Nevertheless, the frequency of $\mathrm{K} 103 \mathrm{~N}$ in our study was greater than in a study of ART-naïve and ART-experienced patients in Shiraz in 2014 [22]. We found high-level resistance to NVP and EFV at 20.3 and $19.7 \%$, respectively, similar to in a previous study of patients on ART in Tehran in 2012 [23].

We recognize the limitations of our study. First, although our series included a large proportion of all patients seen at the Kermanshah referral clinic, they do not represent all HIV patients in the province. Second, all participants were on ART, but we do not have the distinct prevalences of primary and acquired ART resistance mutations. Third, the sample size was small, making statistical inferences difficult, especially compared to other studies in Iran which also suffer from small sample size.

Despite these limitations, the results from the major referral clinic of Kermanshah province are valuable for understanding the epidemiology of HIV in the west of Iran and in our part of the Middle East. Data may also help guide clinical practice for the use of ART regionally. Up to the present, drug resistance genotyping tests have not been routinely performed in our center. Given the high prevalence of drug resistance mutations, we recommended that patients should be tested for drug resistance prior to the initiation of and during the course of treatment, especially when first-line regimens fail. This will allow physicians to prescribe appropriate initial drugs, reduce treatment costs in the long term, and improve the longevity and quality of life of patients.

\footnotetext{
$36 \quad$ Intervirology 2017;60:33-37
} DOI: $10.1159 / 000478701$

\section{Acknowledgements}

We are sincerely appreciative to the laboratory staff of the Department of Microbiology, GolestanUniversity of Medical Sciences, the Center for Behavioral Diseases Consulting in Kermanshah Province, as well as the central office staff who helped in this project. Funding for this study was provided by the Department of Technology and Research, Golestan University of Medical Sciences.

\section{Statement of Ethics}

All procedures performed in studies involving human participants were in accordance with the ethical standards of the institutional and/or national research committee and with the $1964 \mathrm{Hel}-$ sinki declaration and its later amendments or comparable ethical standards. Informed consent was obtained from all participants included in the study.

\section{Disclosure Statement}

The corresponding author declares no conflict of interest.

References

1 Palella FJ, Delaney KM, Moorman AC, Loveless MO, Fuhrer J, Satten GA, et al: Declining morbidity and mortality among patients with advanced human immunodeficiency virus infection. N Engl J Med 1998;338:853-860.

2 Harrigan PR, Hogg RS, Dong WW, Yip B, Wynhoven B, Woodward J, et al: Predictors of HIV drug-resistance mutations in a large antiretroviral-naive cohort initiating triple antiretroviral therapy. J Infect Dis 2005;191:339347.

Golmohammadi/Baesi/Moradi/Farrokhi/ McFarland/Parsamajd 
3 Ambrosioni J, Sued O, Nicolas D, Parera M, López-Diéguez M, Romero A, et al: Trends in transmission of drug resistance and prevalence of non-B subtypes in patients with acute or recent HIV-1 infection in Barcelona in the last 16 years (1997-2012). PLoS One 2015; 10:e0125837.

4 DeGruttola V, Dix L, D'Aquila R, Holder D, Phillips A, Ait-Khaled M: The relation between baseline HIV drug resistance and response to antiretroviral therapy: re-analysis of retrospective and prospective studies using a standardized data analysis plan. Antivir Ther 2000;5:41-48.

5 Richman D, Bozzette S, Morton S, Wrin T, Dawson K, Hellman N, et al: The prevalence of antiretroviral drug resistance in the US (abstract LB-17). Program and abstracts of the 41st Interscience Conference on Antimicrobial Agents and Chemotherapy (Chicago). Washington DC, American Society for Microbiology, 2001.

6 Clavel F, Hance AJ: HIV drug resistance. N Engl J Med 2004;350:1023-1035.

7 Taylor BS, Sobieszczyk ME, McCutchan FE, Hammer SM: The challenge of HIV-1 subtype diversity. N Engl J Med 2008;358:1590-1602.

8 Wainberg MA, Brenner BG: The impact of HIV genetic polymorphisms and subtype differences on the occurrence of resistance to antiretroviral drugs. Mol Biol Int 2012;2012.

9 Seu L, Mulenga LB, Siwingwa M, Sikazwe I, Lambwe N, Guffey MB, et al: Characterization of HIV drug resistance mutations among patients failing first-line antiretroviral therapy from a tertiary referral center in Lusaka, Zambia. J Med Virol 2015;87:1149-1157.
10 Das K, Arnold E: HIV-1 reverse transcriptase and antiviral drug resistance. Part 1. Curr Opin Virol 2013;3:111-118.

11 Jahanbakhsh F, Hattori J, Matsuda M, Ibe S, Monavari S-HR, Memarnejadian A, et al: Prevalence of transmitted HIV drug resistance in Iran between 2010 and 2011. PLoS One 2013;8:e61864.

12 National AIDS Committee Secretariat, Ministry of Health and Medical Education, Islamic Republic of Iran: AIDS progress report. http://wwwunaidsorg/sites/default/files/ country/documents/IRN_narrative_ report_2015pdf 2015.

13 Rhee S-Y, Gonzales MJ, Kantor R, Betts BJ, Ravela J, Shafer RW: Human immunodeficiency virus reverse transcriptase and protease sequence database. Nucleic Acids Res 2003;31:298-303.

14 Johnson VA, Calvez V, Günthard HF, Paredes R, Pillay D, Shafer R, et al: 2011 update of the drug resistance mutations in HIV-1. Topics Antivir Med 2011;19:156-164.

15 HIV Drug Resistance Database. https://hivdb. stanford.edu/.

16 Hamkar R, Mohraz M, Lorestani S, Aghakhani A, Truong HM, McFarland W, et al: Assessing subtype and drug-resistance-associated mutations among antiretroviral-treated HIV-infected patients. AIDS 2010;24(suppl 2):S85S91.
17 Baesi K, Moallemi S, Ravanshad M: Phylogenetic analysis of HIV-1 pol gene: first subgenomic evidence of CRF29-BF among Iranian HIV-1 patients. Asian Pac J Trop Dis 2014; 4(suppl 2):S617-S620.

18 Baesi K, Moradbeigi M, Ravanshad M, Baghban A: Phylogeny and drug resistance of HIV PR gene among HIV patients receiving RT inhibitors in Iran. Asian Pac J Trop Biomed 2016;6:451-454.

19 Farrokhi M, Moallemi S, Baesi K, Ahsani-Nasab S, Gholami M, Sadeghi L, et al: HIV drug resistance and phylogeny profile in naïve and antiretroviral-experienced patients in Tehran, Iran. Intervirology 2016;59:131-136.

20 Mousavi SM, Hamkar R, Gouya MM, Safaie A, Zahraei SM, Yazdani Z, et al: Surveillance of HIV drug resistance transmission in Iran: experience gained from a pilot study. Arch Virol (2010) 2010;155:329-334.

21 Baesi K, Ravanshad M, Ghanbarisafari M, Saberfar E, Seyed Alinaghi SA, Volk JE: Antiretroviral drug resistance among antiretroviralnaïve and treatment experienced patients infected with HIV in Iran. J Med Virol 2014;86: 1093-1098.

22 Naziri H, Baesi K, Moradi A, Aghasadeghi MR, Tabarraei A, Farland WM, et al: Antiretroviral drug resistance mutations in naïve and experienced patients in Shiraz, Iran, 2014. Arch Virol 2016;161:2503-2509.

23 Baesi K, Ravanshad M, Hosseini Y, Haji Abdolbaghi M: Drug resistance profile and subtyping of HIV-1 RT gene in Iranian patients under treatment. Iran J Biotechnol 2012;10: $1-7$.
Drug Resistance Mutations among HIV-Infected Patients, Kermanshah, Iran
Intervirology 2017;60:33-37 DOI: $10.1159 / 000478701$ 